\title{
DESIGN TOOL TO DEVELOP HIGHLY EFFICIENT OPTOMECHATRONIC SYSTEMS - ERRATUM
}

\author{
P.-P. Ley ${ }^{凶}$, J. August and R. Lachmayer \\ Leibniz Universität Hannover, Germany \\ $\bigotimes$ ley@ipeg.uni-hannover.de
}

doi: https://doi.org/10.1017/dsd.2020.270. Published by Cambridge University Press, 11 June 2020.

There were two formatting errors in the above article which are corrected below:

The second sentence of the Introduction on p. 305 should read "The increased application of these components has led inevitably to an advancement of mechatronic systems to optomechatronic systems."

The final sentence on p. 305 should read "Even though the development of optical systems is strongly application-oriented, in most cases it results in a compromise between image quality and efficiency of the optical system."

The Publisher apologises for these errors.

\section{Reference}

Ley, P., August, J. and Lachmayer, R. (2020), "Design Tool to Develop Highly Efficient Optomechatronic Systems," in Proceedings of the Design Society: DESIGN Conference. Cambridge University Press, Vol. 1, pp. 305-314. https://doi.org/10.1017/dsd.2020.270 